gens such as ethyl methanesulphonate, and is recessive in cell hybrids. The clue that $t s \mathrm{H} 1$ has a primary defect in protein synthesis came when the rates of DNA, RNA and protein synthesis were examined after cells were placed at the nonpermissive temperature. Both DNA and RNA synthesis decline with a half-life of between 5-8 h; notably, protein synthesis shuts off almost immediately and is down to $5 \%$ of control values by $1 \mathrm{~h}$.

Following this lead, Thompson et al. looked for various amino-acylated tRNAs by feeding cells ${ }^{14} \mathrm{C}$-amino acids in the presence of cycloheximide and actinomycin D. Wild-type cells and a temperature-resistant revertant showed equal amounts of leucyl-tRNA at both $34^{\circ} \mathrm{C}$ and $40.5^{\circ} \mathrm{C}$; $t s \mathrm{H} 1$ had normal amounts of all the amino acyl-tRNAs at $40.5^{\circ} \mathrm{C}$, except leucyl-tRNA which was reduced more than 100 times. Direct assay in vitro of the leucyl-tRNA synthetase from $t s \mathrm{H} 1$ showed that it is the synthetase itself which is $t s$.

The second report, by Sharp, Capecchi, and Capecchi (70, 3145), is a study of the properties of the favourite enzyme of the somatic cell geneticisthypoxanthine phosphoribosyl transferase (HPRT) -in variants of the mouse L cell. Cells that have a normal HPRT are extremely sensitive to the purine analogues, 8-azaguanine (8AG) and 6-thioguanine; revertants can be isolated using the Littlefield technique of blocking de novo purine biosynthesis with aminopterin and simultaneously providing hypoxanthine and thymidine ('HAT' selection). While looking for nonsense suppressors, Sharp et al. examined the kinetic properties and heat stability of HPRT among such HATresistant revertants. Several revertants grew equally well in both medium used to isolate HPRT-negative cells (8AG) and in medium used to isolate HPRTpositive revertants (HAT). These revertants had high concentrations of HPRT.

Initially, this seems to be a surprising, if not a slightly disturbing, result, though it would be expected if the revertant enzyme had a decreased affinity to $8 \mathrm{AG}$, but had the normal $K_{m}$ for hypoxanthine. This is precisely what Sharp et al. report for one such revertant, suggesting that a structural change has occurred in the enzyme. Another class of revertants possessed a very heatlabile HPRT, again providing strong evidence of structural changes in the enzyme as the result of mutation.

These two reports, taken together with previous findings of $8 \mathrm{AG}$-resistant variants that contain material that cross-reacts immunologically with HPRT but have no enzymatic activity (Beaudet et al., Proc. natn. Acad. Sci., U.S.A., 70, 320) and $\alpha$-amanitinresistant mutants due to an altered RNA polymerase II (Chan et al., ibid., 69, 3119), should help to quiet the critics. It seems that at least some variants are mutants.

\section{Analytical techniques for museums}

from a Correspondent

THE Society for Analytical Chemistry (Midlands Region) recently cooperated with the United Kingdom Group of the International Institute for Conservation in organising a symposium at the Birmingham Museum and Art Gallery on December 4. The scope of the contributions concerned both the present types of chemical analytical methods used in museum laboratories and also reviews of techniques which, although used increasingly in chemistry research in general, may also have applications to the examination of museum objects.

B. W. Fitzsimmons (Birkbeck College, London) described the theory and practice of Mössbauer spectroscopy and its applications to the study of ${ }^{57} \mathrm{Fe}$ and ${ }^{117} \mathrm{Sn}$ nuclei. As this technique gives information on the chemical environment of iron and tin, its potential use in museums is in the examination of clays and iron oxide pigments which may be complex mixtures of ferrous and ferric compounds. M. Thompson (University of Technology, Loughborough) dealt with photoelectron spectroscopy. Using $X$-ray excitation all elements except hydrogen can be detected in small samples, and it is possible to deal with many mixed oxide systems. The extreme sensitivity and high selectivity of the antigen-antibody reactions of, for example, proteins in immunological methods (J. N. Miller, University of Technology, Loughborough) which are already used in forensic science and food science suggest that they could be applied to paintings and other art work to reveal the media used by the artist. A key issue is whether antigen activity survives over long periods and this requires investigation.

After descriptions of potential new techniques, the methods used at present and results obtained in different museum laboratories were then described. J. Mills (National Gallery, London) has used infrared spectrometry and chromatography, principally GLC, to identify organic materials in art objects. Organic materials encountered in antiquities, especially paintings, are often complex natural products, but GLC of terpenoids (that is, resins) has provided new information on their identification and the chemical changes undergone over long periods. Ancient bronzes and faience in numbers running into the thousands have been analysed by $\mathbf{H}$. McKerrell (National Museum of Anti- quities of Scotland) using the version of non-dispersive X-ray fluorescence which he has developed. A rapid non-destructive method such as this has great potential for analytical surveys of large groups of museum objects. Such analyses have an important bearing on basic archaeological problems of trade contacts and sources of raw materials such as tin. In another laboratory (M. J. Hughes, Research Laboratory, British Museum) a combination of qualitative spectrographic and quantitative atomic absorption analysis has been used, because these methods are sufficiently sensitive for analyses of the small samples only which can be taken from museum objects.

Where expensive analytical equipment is not available, J. Hedley and A. Cumming (Courtauld Institute of Art, London) described how optical mineralogy, microchemical analysis and spot tests can be applied to inorganic materials used in paintings, and for organic compounds solubility tests and selective staining have been successfully applied.

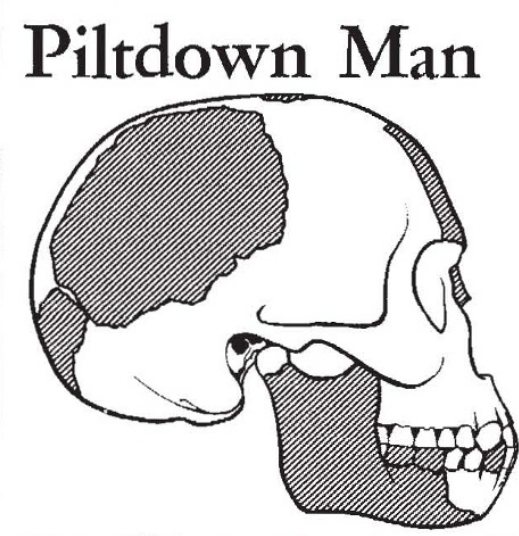

THE Piltdown Man hoax still arouses curiosity and indeed was the subject of a recent British television programme some 60 years after the bits of skull and jawbone were found in a remote corner of Sussex. The British Museum (Natural History) has therefore done a service to the ordinary person who likes a scientific detcctive story, by producing a slim guide (The Piltdown Man Hoax, Palaeontology Leaflet No. 2, pp. 6; 7p) which sets out simply how the Piltdown remains came to be found, names the persons chiefly responsible for identifying the fragments, describes how the hoax was exposed at the museum and elsewhere between 1949 and 1953 and explains how, in 1973, the museum can say confidently "none of the Eoanthropus fragments can be considered fossil or in any way part of man's ancestry". 